system whose harmonious operation depends upon an agent which dominates all the elements or all the substance within the system. The lesser mechanism of the autonomous element in the one hypothesis and the greater control mechanism of the other hypothesis may equally well be regarded, if one is philosophically so disposed, as being the marvelous outcome of the accidental conspiracy between molecular structure and a selectively acting environment. Upon the other hand, a living being in which extensive groups of elements, physically more or less distinct and even heterogeneous in character, are in a large way dominated by agents which mold form and direct action, offers to the vitalist, of whatever type, a realm in which nonphysical, ultra-physical or psychic factors and forces may be created and set going to the limit of his bent.

HaRVARD UNIVERSITY

HERBERT W. RAND

(To be concluded)

\section{THE GROWTH OF CHILDREN}

Prevrous investigations have shown that the rate of growth of the body, measured by weight and stature, increases very rapidly until the fifth month of fetal life. From that time on the rate of growth decreases, first rapidly, then more slowly until about four years before the age of puberty. During adolescence the rate of growth is considerably accelerated, and decreases again rapidly after sexual maturity has been reached. Thus the curve of growth represents a line which possesses a very high maximum at about the fifth month of fetal life. It decreases rapidly, and has a second, although much lower maximum shortly before sexual maturity is reached, and not long afterwards reaches the zero point.

The bulk of the body of girls and boys is approximately equal until the period of adolescence. Since this sets in much earlier in the female than in the male, the concomitant acceleration also sets in at an earlier time, with the result that for a few years girls are larger than boys.

The periods of most active growth of the various parts of the body differ considerably. Nevertheless, it would seem that the characteristics of the curve of growth as here outlined are repeated in many if not in all organs and parts of the body. For instance, although the head reaches nearly its full size at an early time, so that its rate of growth shows a much more rapid decrease with age than that of the bulk of the body, there is a slight acceleration of growth during the period of adolescence.

It might seem, judging from the data just mentioned, that the difference between the sexes does not develop until the period of adolescence; but a study of the eruption of the teeth which I made a number of years ago, and the more recent interesting investigations by Rotch and Pryor on the ossification of the carpus, show that the difference in physiological development between the two sexes begins at a very early time, and that in the fifth year it has already reached a value of more than a year and a half.

I give here a tabular statement of the available observations:

\begin{tabular}{|c|c|c|c|}
\hline & \multicolumn{2}{|c|}{ Age in Years } & \multirow{2}{*}{$\begin{array}{c}\text { Differ- } \\
\text { ence }\end{array}$} \\
\hline & Boys & Girls & \\
\hline Ossification of scaphoid................ & 5.8 & 4.2 & -1.6 \\
\hline Ossification of trapezoid................ & 6.2 & 4.2 & -2.0 \\
\hline 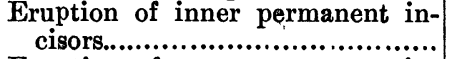 & 7.5 & 7.0 & -0.5 \\
\hline 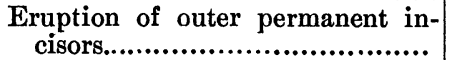 & 9.5 & 8.9 & -0.6 \\
\hline Eruption of bicuspids................... & 9.8 & 9.0 & -0.8 \\
\hline Minimum increase of annual growth & 10.3 & 8.2 & -2.1 \\
\hline Eruption of canines................... & 11.2 & 11.3 & +0.1 \\
\hline $\begin{array}{c}\text { Maximum increase of } \\
\text { growth }\end{array}$ & 13.2 & 11.2 & -2.0 \\
\hline 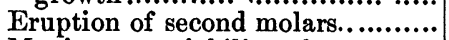 & 13.2 & 12.8 & -0.4 \\
\hline Maximum variability of stature.... & $\mid 14.8$ & 12.4 & -2.4 \\
\hline
\end{tabular}

These data are not very accurate and must be considered a first approximation only.

When we remember that growth depends upon physiological development, it will be recognized that we must not compare the stature of girls of a certain age with that of boys of the same age, but that from the fourth year on a girl of a certain age should be com- 
pared with a boy a year and a half older than she is.

If this view is correct, then it appears that the relation in size of the two sexes persists even in childhood.

I think no better proof can be given of the correctness of this view than the peculiar behavior of those parts of the body which complete their growth at a very early time; for instance, that of the head. The total amount of the growth of the head from the second year on is very slight. If, therefore, girls are ahead of boys in their development by about a year and a half or two years, the total amount of growth of the head in their favor will be the small amount of growth accomplished during this period of a year and a half or two years. If, then, there is a typical difference between the size of the body of male and female in childhood of the same character as found in adult life, then the head of the girl ought to be at all periods smaller than the head of the boy; and this is what actually happens. The phenomenon has been interpreted as indicating a less favorable development of the head of the woman; but the previous remarks show that it is obviously due solely to the different rate of physiological development of the two sexes. The results of psychological tests which show very generally that girls do better than boys of the same age, may be another expression of the general acceleration of their development.

Based on these observations, we may speak of a curve of growth and development of the whole body and its organs which has characteristic values for each sex and for each moment in the life of the totality of individuals that compose a social group. Not each individual, however, passes through these stages of development with equal rapidity. The mean square variability of the chronological age at which a certain point in the physiological development of an individual is reached is contained in the following table:

\begin{tabular}{|c|c|c|}
\hline Age & Observations & $\begin{array}{l}\text { Varia- } \\
\text { bility }\end{array}$ \\
\hline 0.0 & Pregnancy & \pm 0.04 \\
\hline 0.6 & First incisors & \pm 0.21 \\
\hline
\end{tabular}

1.6 First molars .............. \pm 0.31

4.2 Ossification of scaphoid bone, girls \pm 1.4

4.2 Ossification of trapezoid bone, girls \pm 1.2

5.8 Ossification of scaphoid bone, boys \pm 1.1

6.2 Ossification of trapezoid bone, boys \pm 1.3

7.0 Inner permanent incisors, girls ... \pm 1.6

7.5 Inner permanent incisors, boys ... \pm 1.4

8.9 Outer permanent incisors, girls ... \pm 2.1

9.0 Bicuspids, girls $\ldots \ldots \ldots \ldots \ldots \ldots \pm 2.8$

9.5 Outer permanent incisors, boys ... \pm 2.1

9.8 Bicuspids, boys $\ldots \ldots \ldots \ldots \ldots \ldots \pm 1.6$

11.2 Permanent canines, boys ....... \pm 1.4

11.3 Permanent canines, girls ....... \pm 1.0

12.7 Beginning of pubescence, boys $\ldots \pm 1.6$

12.8 Second molars, girls . . . . . . . . \pm 1.6

13.2 Second molars, boys $\ldots \ldots \ldots \ldots \pm 2.0$

14.6 Completed pubescence, boys .... \pm 1.1

14.9 Puberty, girls $\ldots \ldots \ldots \ldots \ldots \ldots \pm 2.0$

19.3 Wisdom teeth, boys $\ldots \ldots \ldots \ldots \ldots \pm 2.1$

22.0 Wisdom teeth, girls $\ldots \ldots \ldots \ldots \ldots \pm 1.8$

35.0 Preauricular wrinkles $\ldots \ldots \ldots \ldots \pm 6.6$

36.5 Hair on tragus $\ldots \ldots \ldots \ldots \ldots \ldots \pm 8.3$

44.5 Menopause .............. \pm 5.3

62.5 Death due to arterial diseases, men \pm 13.2

It appears from this table, which may be represented in the form of a curve, that the variability of the physiological stages of development increases very rapidly-roughly speaking, so that its logarithm is about proportional to the actual age, or, to use the term applied by Dr. Crampton and Professor Rotch, to the "chronological age." The causes that lead to this rapidly increasing variability are so far entirely unknown. It is certain, however, that there must be definite causes at work which bring about this phenomenon; for, if the variability were due to accidental causes only, it would increase considerably slower than in a ratio proportional to the increasing age. The study of the general curve indicating the increase of variability in physiological development indicates an irregularity at the time of approaching maturity. At this period the variability seems to increase at an unusually rapid rate, and either to be stationary or to decrease again at a later time.

I have spoken here of the variability of the physiological development of the body as though this were a unit. In 1895, in a dis- 
cussion of Professor Porter's observations on the growth of school children in St. Louis, I pointed out the fact that a general variability in physiological development accounts for the close correlation between the distribution of ages in school grades and the size of the body and its organs; and this problem was later on worked out by myself in conjunction with Dr. Clark Wissler in regard to various measurements. These correlations have also been proved in a most interesting manner by Dr. Crampton's observations on pubescence, and by Professor Rotch's and Pryor's study of the development of the epiphyses and carpal bones. It is true that a close correlation between the status of the physiological development of the various parts of the body exists, but there exists also a certain amount of variability in the development of an organ when another one has reached a definite stage. The correlation is so close that the condition of the bones or that of pubescence gives us a better insight into the physiological development of the individual than his actual, chronological age, and may therefore be advantageously used for the regulation of child labor and school entrance, as Rotch and Crampton advocate; but we must not commit the error of identifying physiological development with physiological age, or of considering chronological age as irrelevant. The clearest proof that is available is found in the data relating to increase of stature, and in observations on pubescence made according to Dr. Crampton's methods. Bowditch was the first to investigate the phenomena of growth of individuals who are short or tall at a given age, but his method was based on a statistical error. Later on I showed that retarded individuals possess a late acceleration of growth, and these results were amplified by studies made by Dr. Beyer and Dr. Wissler. Recently I had occasion to make a more detailed statistical analysis of the phenomena of growth, which show that individuals whose prepubertal accelerated growth begins late in life have rates of growth that exceed by far those of the normal individual; in other words, that among the retarded individuals the whole energy required for growth is expended in a very brief period. In the case of stature the phenomenon is complicated by the great differences in hereditary stature among the various parts of the population. It appears more clearly in observations on pubescence. The observations indicate that if the first pubic hair appears in one group of boys at eleven and a half years, in another at fifteen and a half years, it will take the former much longer than the latter to attain the full development of pubic hair, and the rate of change found among them will be much greater than that of normally developed individuals. Although further data are required to determine this point definitely, it is certain that we must not assume that individuals who exhibit the same stages of physiological development are the same, physiologically speaking, no matter what their actual age may be; on the contrary, the past and prospective physiological changes in their bodies will proceed in different manners. It is clear, therefore, that the greater the retardation or acceleration in any one particular respect, the greater will also be the disharmonies that develop in the body, since not all the other organs will follow the same rate of acceleration and retardation.

The causes of these phenomena are unknown; but we may perhaps venture on the hypothetical explanation that all the cells of the body undergo certain progressive changes with increasing age, and that the internal secretions which become active at the time of puberty exert a stimulus upon the cells which causes accelerated growth in the cells, and that the intensity of this influence depends also upon the state of development of these cells. This may refer to the whole body as well as to the glands that have a direct influence upon the rate of growth. In retarded individuals many of the cells have advanced in their development more nearly normally than the groups of cells involved in sexual maturity; and when their action sets in, the cells of the body are stimulated much more vigorously than the less developed ones of an individual that reaches maturity at an earlier time. This hypothesis, however, would have to be tested experimentally. It is intended only to bring 
nearer to our understanding the complicated phenomena of retarded and accelerated growth.

It seems very likely that the abnormally large amount of energy expended upon rapid growth during a short period is an unfavorable element in the individual development. A study of the phenomena of growth of various groups of the same population has shown that early development is a concomitant of economic well-being, and that a characteristic of the poor is the general retardation in early childhood, and the later rapid growth. It follows from this that there is a corresponding, although not equal, retardation in early mental development, and a crowding of developmental processes later on, that probably place a considerable burden on the body and mind of the poor, which the well fed and cared for do not bear. The general laws of growth show also that a retardation kept up for an unduly long period can not be made up in the short period of rapid growth; so that it would seem that, on the whole, excessive retardation is an unfavorable element in the growth and development of the individual. Whether there are similar disadvantages in a considerable amount of early acceleration is not so clear.

Franz Boas

\section{COLUMBIA UNIVERSITY}

\section{THE WORK DONE BY THE GERMAN SUB- COMMITTEE ON THE TEACHING OF MATHEMATICS ${ }^{1}$}

I REGRET very much, that Mr. F. Klein, Göttingen, the president of the German subcommittee of the International Commission on the teaching of mathematics, is not able to come to Cambridge. It thus happens that I have the honor, in his place, of presenting to you the following short report of the present state of the work done in Germany.

When we consider the historical development of the German empire, it is very evident that we should not expect to find a homogeneous system of schools, controlled by a central board of education, as is usually the case in

${ }^{1}$ Report presented at the meeting of the Fifth International Congress of Mathematicians, at Cambridge (England), August 23, 1912. other countries. The various sections of the German people may be looked upon as different sources of the stream of German culture. Furthermore, the religious reformation tended to increase the variety of the German schools; for while in some parts of Germany the schools of to-day can be traced directly to the ancient cloister-schools, in other sections of the country there is not such a connection apparent. And finally the modern development of Germany from an agricultural state to an industrial one has also had a large influence on the formation of schools, so that a great difference in types must be expected and actually does exist.

A recognition of all these influences, the political, the religious and the economical, is essential to a complete understanding of German education, and they are therefore in evidence in the general plan of the German report as well as in the individual essays of which it consists.

The German report ${ }^{2}$ is composed of 5 volumes, treating:

I. The secondary schools of northern Germany.

II. The secondary schools of southern and middle Germany.

III. Special problems of the secondary mathematical instruction.

IV. The mathematics at the technical schools.

V. The teaching of mathematics in elementary schools, and in the seminaries or training schools for elementary teachers.

These five volumes will comprise 36 individual reports and $I$ have the honor to present 27 of them to the congress.

The German subcommittee has succeeded in engaging a staff of specialists in the various fields of mathematical instruction, and it has taken care to harmonize all the single reports with the general plan. The president, Mr. Klein, had the general supervision of all

2"Abhandlungen über den mathematischen Unterricht in Deutschland, veranlasst durch die Internationale Mathematische Unterrichtskommission,' Herausgegeben von F. Klein, Leipzig, B. G. Teubner. 